\title{
DIASTEMATOMYELIA
}

\section{A CRITICAL SURVEY OF 24 CASES SUBMITTED TO LAMINECTOMY*}

\author{
BY
}

\author{
C. C. MICHAEL JAMES and L. P. LASSMAN \\ From the Regional Neurological Centre, Newcastle General Hospital, and \\ W. J. Sanderson Orthopaedic Hospital, Newcastle upon Tyne
}

We have previously described a syndrome associated with spina bifida occulta where there is a congenital abnormality, extrinsic to the spinal cord, causing neurological deficit in the lower limbs, bladder and bowel. We have operated on more than 70 patients and of the first 60,24 had diastematomyelia. It is our purpose in this communication to describe the forms of diastematomyelia found and to analyse the clinical findings. A few of these patients have been previously reported on individually in detail with photographs taken at operation (James and Lassman, 1958, 1960, 1962a, b; Lassman and James, 1963).

Diastematomyelia, which is a bifid state of the spinal cord, is an intrinsic anomaly and requires no treatment. The spinal cord is known to be able to function normally in such cases but it may be affected by associated extrinsic abnormalities that interfere with conduction, either directly or indirectly. It does not seem to be sufficiently recognized that this condition is indistinguishable clinically from the other types of lesion that are associated with the spinal cord in spina bifida occulta and that produce a similar pattern of neurological deficit.

In many cases the two spinal cords are contained within a single dural tube without an intervening septum, but when each spinal cord has its own dural sheath there is always a septum of bone, cartilage, fibro-cartilage or fibrous tissue that can prevent the spinal cord from 'ascending' within the vertebral canal as the vertebral column grows in length, or it can cause pressure laterally on one or other spinal cord. The results of septal pressure are, therefore, more likely to be seen in childhood although they have been reported in adult life.

\section{Operation Findings}

Every case had spina bifida of a greater degree than a simple split in the spinous process of Sv.1 as

\footnotetext{
* A paper read at a meeting of the British Association of Paediatric Surgeons in Sheffield, July 1963.
}

seen on radiography. The spinal cord abnormality was found in close proximity to the laminal defects but not always at the same level. This is particularly notable in cases with a bone septum. In these the laminae continuous with the septum always appeared normal, and in fact the bone septum is frequently unnoticed in plain x-ray films because of its resemblance to a spinous process in the antero-posterior view. Myelography demonstrates diastematomyelia in the majority of cases (Gryspeerdt, 1963).

Cases with Separate Dural Tubes. There were 13 of these and each of them had a septum external to the two median layers of dura. The septum was clearly affecting the spinal cord in six cases, in one by lateral pressure and in the other five by preventing ascent. The dura is also a factor causing injury since it is the first tissue to come in contact with the septum, and where ascent is being prevented the tube of dura may have a constricting effect as well as being the point of contact with the caudal junction of the two spinal cords (Fig. 1).

The degree of ossification of the septum was not related to age, for in one child of 10 years the septum was fibrous and yet in another child of 2 years it was well ossified.

In the operation, it has been found safer and easier to remove the septum before opening the dura which acts as a protective covering for the spinal cord. Although the septum usually occupies the whole of the space between the two dural tubes, the diastematomyelia within the dura is frequently of greater extent and therefore not so closely adherent. This allows a margin of safety in manipulation of the instruments. The median dura between the spinal cords is excised later when the intrathecal situation is plainly visible and it can be ensured that nothing is left that might interfere with any future need for change in position of the spinal cord within the vertebral canal during the course of normal growth.

In the majority of our cases, the broadest attachment of the septum has been dorsal, and where it was 


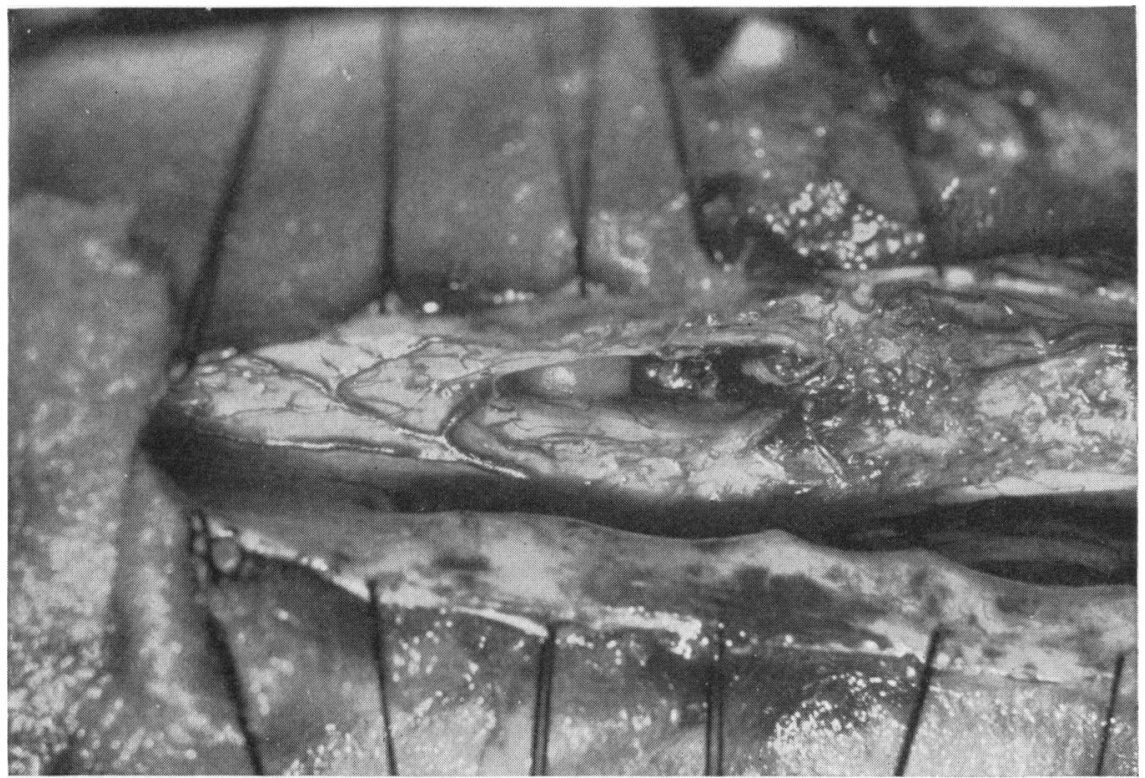

Fig. 1.-Appearance at the end of operation. The dura is open. The bone septum (Lv. 3) and the median dura between the two dural tubes have been removed. Diastematomyelia $(2 \mathrm{~cm}$.) is in the centre; the bone septum had occupied the caudal half and had been pressing on the caudal spinal cord which is swollen and engorged (to the right of the photograph) as compared with normal spinal cord (to the left).

ossified the ventral attachment has been narrow and frequently more fibrous than bony, which makes avulsion of the septum from its attachment deep down very much easier. When the deep attachment is broad and osseous its removal is more difficult. It is a misconception to regard a septum as growing from a vertebral body or from a neural arch. Bone develops only in preformed tissues and therefore it is pointless to discuss whether a septum originates dorsally or ventrally. The abnormality results from failure of normal development in early embryonic life and the septum represents mature tissues formed from aberrant embryonic cells.

Cases with Single Dural Tube. None of these 11 cases had a septum although one had a fatty fibrous plug between and adherent to the two spinal cords but it was not adherent ventrally; this plug was continuous dorsally through the dura to a large subcutaneous lipoma in the lumbar region. In every case the bifid spinal cords rejoined caudally to form an apparently normal spinal cord. In only one case (not in the series) have we seen a condition that might have been a bifid conus or duplicated filum terminale. There seems to be no particular pathological significance in the extent of the diastematomyelia. It has varied between 1 and $9.5 \mathrm{~cm}$., although in one case the distance was not measured because the diastematomyelia extended beyond the surgical exposure. Where there is diastematomyelia the tracts that normally cross from one side to the other must do so cranial or caudal to the division of the spinal cord, but in a few of our cases there have been intervening bands that must be regarded as commissural.

Usually the space between the two spinal cords is quite obvious but occasionally the two spinal cords are very closely apposed, their dorsal cleft being marked by a longitudinal dorsal blood vessel in the midline. This fact has become evident in a case operated on only recently and therefore not included in this series; such a finding, however, is unlikely to be of any clinical significance. There may have been other cases in which this was not noticed at operation.

The associated extrinsic abnormality most commonly found in this series was one or more bands that microscopy has shown were sometimes nerves and sometimes fibrous tissue. At one end they were connected with one bifurcation of the spinal cord and at the other end either to the dura or through the dura to a neural arch (Table 1). They are almost always angulated in their course and since some cases have shown improvement following division of the offending band from its attachment to the dura, we can only postulate that they have been 


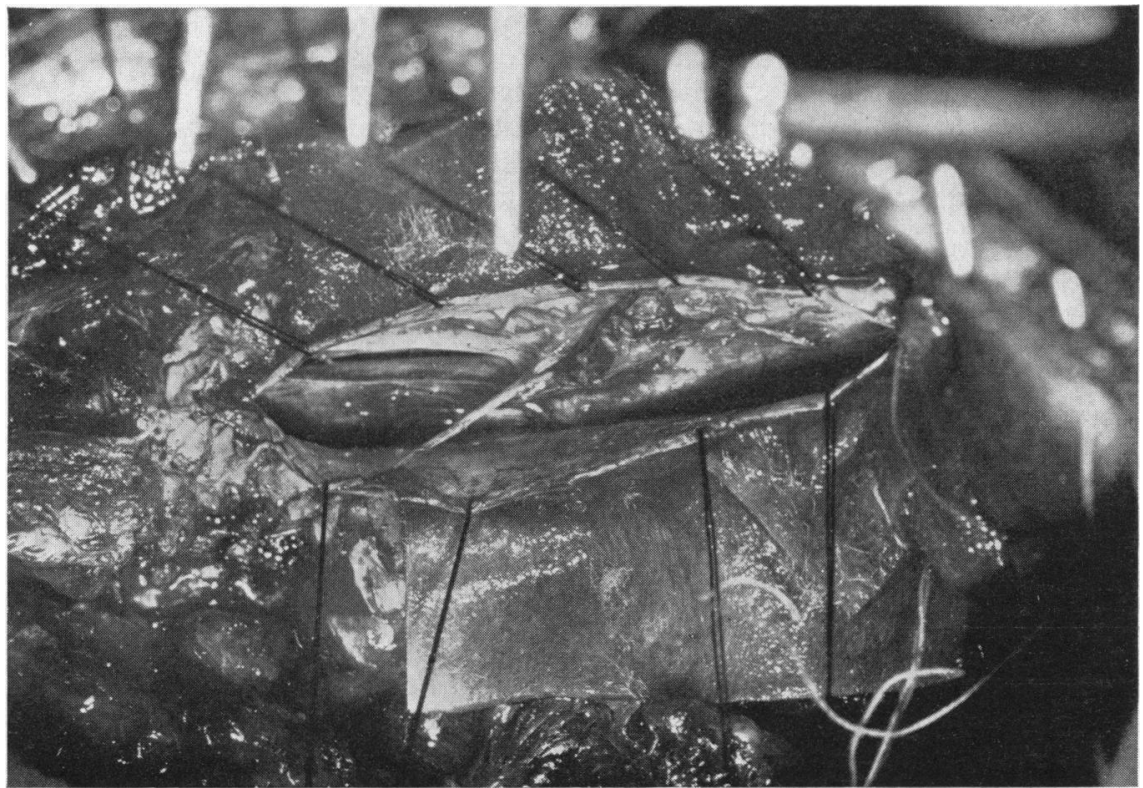

FIG. 2.-Appearance at operation after opening the dura mater (single tube). An extradural band extended vertically from Lv. 2 neural arch to attach to the dura and continued intrathecally in a caudal direction (left of centre) to attach to the caudal junction (centre) of the two spinal cords (seen on the left). The diastematomyelia was $3 \mathrm{~cm}$. long. Normal spinal cord to the right of the exposure (Lv. 3 and 4 level)

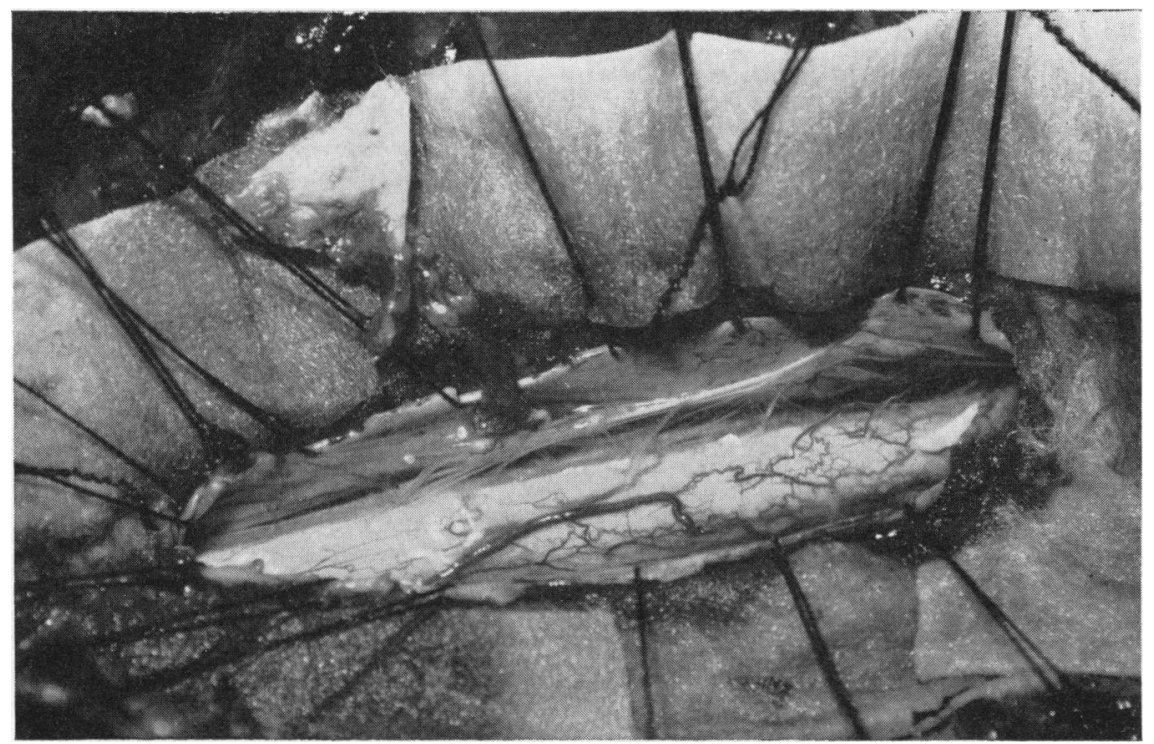

FIG. 3.-Dura open and diastematomyelia $9.5 \mathrm{~cm}$. long seen throughout the exposure; neither bifurcation is shown. In the centre is a nerve passing from the left to the right where it penetrates the dura (Lv. 2 neural arch level). It receives contributions from both spinal cords and at its origin it lies over and conceals commissural bands which connected through the dura to the neural arch of Lv. 1; this connexion can be seen left of centre lying upon the surrounding swabs. There was a third similar band from the neural arch of Tv. 12, which is not shown. The two spinal cords were of equal size although the photograph suggests that the left one was very large. 
exerting a traction effect. In some cases there has been more than one band, one attaching at each bifurcation and one or more to the commissural bands between the two spinal cords, all having a dorsal attachment to the dorsal dura as well, often continuing extradurally to the neural arches (Figs. 2 and 3).

TABLE 1

SINGLE DURAL TUBE-11 CASES: OPERATION FINDINGS

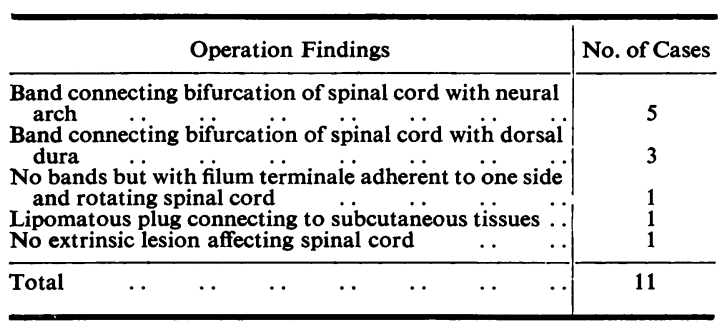

TABLE 2

11 CASES WITH SINGLE DURAL TUBE: RESULTS OF OPERATION

\begin{tabular}{|c|c|c|}
\hline Before Operation & $\begin{array}{l}\text { No. of } \\
\text { Cases }\end{array}$ & After Operation \\
\hline $\begin{array}{l}\text { Reflexes normal } \\
\text { Reflexes abnormal }\end{array}$ & $\begin{array}{l}2 \\
4 \\
3 \\
2\end{array}$ & $\begin{array}{l}\text { Reflexes normal, no further deteri- } \\
\text { oration in gait or foot shape. } \\
\text { One or more reflexes changed to } \\
\text { normal. } \\
\text { Reflexes unchanged, gait improved. } \\
\text { Reflexes unchanged, no further } \\
\text { deterioration in gait or foot shape. }\end{array}$ \\
\hline Total & 11 & \\
\hline
\end{tabular}

The bands are aberrant posterior nerve roots either still functioning or atrophic. In the embryo the posterior nerve roots and ganglia are formed from the cells of the neural crest; consequently any interference with the development of the neural tube is likely to give rise to aberration in the migrations of the developing cells.

The single case in which no extrinsic lesion was found was known, as the result of myelography, to have two lesions; the greater defect in the thoracic region was explored and the lesser defect in the lower lumbar region was ignored. This was an early case and the first one in which the myelographic pattern in the lumbar area had been seen. Subsequent experience has produced several such cases and we now know that this child has another area of diastematomyelia with a band attaching to the dura and possibly the neural arch. The area has not been explored since the child's clinical state has remained unaltered in the two years following her thoracic laminectomy. We now believe that in any case with two widely separated lesions it is likely to be wiser to explore the lumbar region first. In theory the clinical picture should indicate the level of the spinal cord which is being affected, but since the conus medullaris is rarely, if ever, at the normal level in these cases, and the pressure and traction effects on the spinal cord are so diffuse, it is impossible to be accurate in localizing the site of an extrinsic lesion.

In many of these cases it is difficult to know why there should be any neurological deficit and why operation should make any difference. Table 2 shows an analysis of the results of operation on these 11 cases in a follow-up of five months in one case, six months in another and 14 months to three years in the remainder; but it is not the purpose of this communication to discuss the results of operations, although they are encouraging.

\section{Clinical Findings}

The syndrome of early neurological changes occurring in spina bifida occulta, which we have described, is not the only mode of presentation and development. Spina bifida occulta is a lesser degree of spinal dysraphism than spina bifida aperta (myelocele and meningomyelocele), but in some cases the neurological deficit can become as severe and in exactly the same way. Consequently, the appearance in a clinic of a child with lower limb abnormalities or bladder or bowel disturbances resembling those found in spina bifida cystica should immediately lead to the investigation of the vertebral column to make sure that there are no laminal defects. The clinical findings in diastematomyelia are no different from those in other cases of spina bifida occulta.

Table 3 shows an analysis of the symptoms with which our cases presented. Pes cavovarus is the earliest evidence of progressive neurological deficit and is usually unilateral to begin with. A number of children have some form of foot abnormality at birth. Those that start with club feet are commonly not diagnosed as cases of spinal dysraphism until a late stage and it is interesting to note the number in Table 3. Those that start with calcaneous or flat feet and suddenly develop cavovarus are sufficiently disconcerting to the therapist for the diagnosis to be made without much difficulty. If sensory changes develop so that there is trophic ulceration, a congenital club foot is clearly associated with neurological deficit.

Pes valgus is a later stage of deterioration than cavovarus, and the change from the latter is 
unexpected and consequently striking. Where there is an external cutaneous manifestation on the back, e.g. hypertrichosis, lipoma, naevus or dermal dimple, associated with foot abnormality with or without reflex changes the diagnosis is easier.

Our single case with poor circulation in the legs (James and Lassman, 1958) had the discoloration so commonly seen in spina bifida cystica and in cases that have suffered from poliomyelitis in the past.

Table 4 is an analysis of the clinical findings in the 24 cases under discussion, and the only notable point that may be significant is that there was no case with bowel or bladder disturbance; but paraplegia is reported to have occurred in cases with a bone septum. In every other respect, Table 4 shows no feature to distinguish these cases from the other 36 cases of our series that did not have diastematomyelia.

In the syndrome we have previously described, a short leg and foot was one of the basic factors and Table 4 shows how commonly it is found. Of the four cases in this group that were without neurological deficit, one had circulatory changes in the legs, one had a large subcutaneous lumbar lipoma, one had weakness of the leg, and one had hypertrichosis. The three with normal limbs had marked external manifestations that warranted myelographic investigation, and in every case an abnormality was demonstrated.

Table 5 shows the cases that had external cutaneous manifestations on the back, usually in the lumbar or lumbosacral region. These manifestations occur randomly throughout our series of 60 cases, although it has been suggested by others that hypertrichosis is an indication of underlying diastematomyelia; this is not so.

\section{Summary}

In a series of 60 consecutive cases of spina bifida occulta submitted to laminectomy because of abnormality of the spinal cord or cauda equina, diastematomyelia was found in 24 , and these cases are surveyed.

Thirteen cases had separate dural tubes for each spinal cord and in every case there was a dorsiventral extradural septum as well; 11 had a single dural tube enclosing both spinal cords and none had a septum between.

The clinical appearances in these 24 cases of diastematomyelia show no characteristic to distinguish them from the other 36 in the series.

It is the accompanying extrinsic lesion affecting the spinal cord that is of clinical importance and not the diastematomyelia.
TABLE 3

PRESENTING SYMPTOMS IN 24 CASES

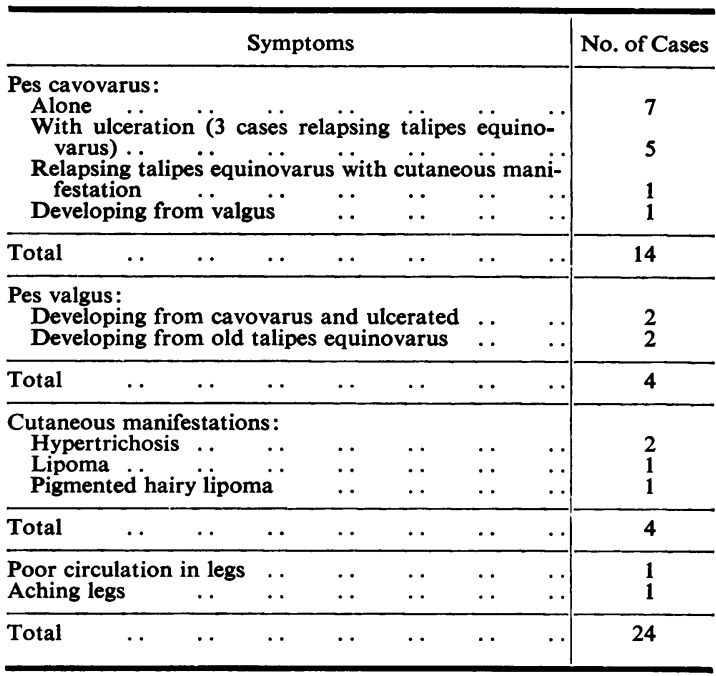

TABLE 4

CLINICAL SYNDROME IN 24 CASES

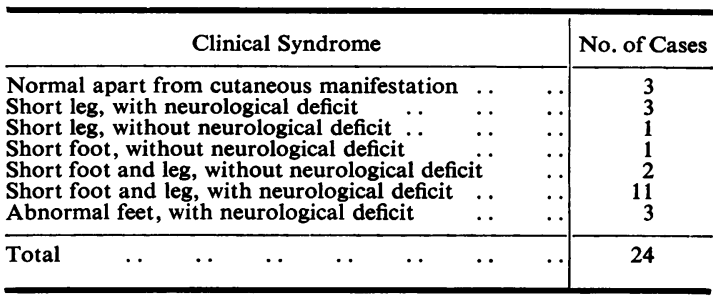

* None had bladder or bowel disturbance

TABLE 5

CUTANEOUS MANIFESTATIONS ON THE BACK (24 CASES)

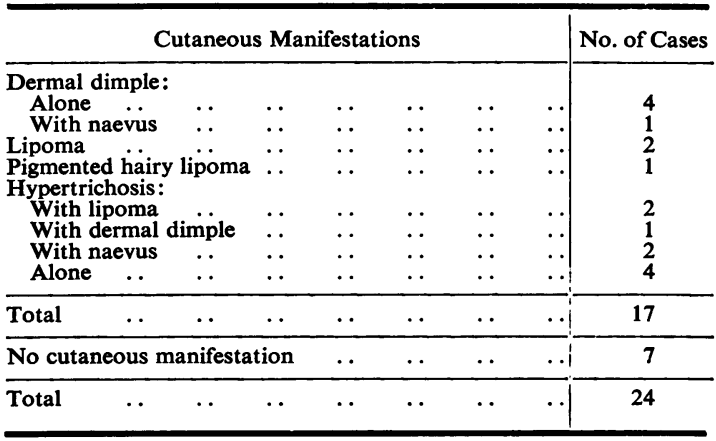


We are glad to acknowledge our continued indebtedness to Dr. Gordon Gryspeerdt, Neuroradiologist, Dr. Douglas Whitby, Anaesthetist, and Sister C. Palfreyman, Ward Sister, who have collaborated closely with us in this work.

Mr. R. W. Ridley and Mrs. P. Bone of the University Department of Medical Photography have photographed all our cases.

The Scientific and Research Committee of the Newcastle Regional Hospital Board has provided assistance and finance for morbid anatomical investigations related to this work.

\section{REFERENCES}

Gryspeerdt, G. L. (1963). Myelographic assessment of occult forms of spinal dysraphism. Acta radiol. (Stockh.), n.s., 1, 702 .

James, C. C. M. and Lassman, L. P. (1958). Diastematomyelia. Arch. Dis. Childh., 33, 536.

- (1960). Spinal dysraphism. An orthopaedic syndrome in children accompanying occult forms. ibid., 35, 315 . (1962a). Spinal dysraphism. The diagnosis and treatment of progressive lesions in spina bifida occulta. J. Bone Jt Surg. 44B, 828 .

- (1962b). Spinal dysraphism. Spinal cord lesions associated with spina bifida occulta. Physiotherapy, 48, 154.

Lassman, L. P. and James, C. C. M. (1963). Lumbosacral lipomata and lesions of the conus medullaris and cauda equina. Excerpta med. (Amst.), Int. Cong. Series, No. 60, p. 139. 